\title{
Scanning Electron Microscopy Characterization of Aluminized Layer Formation on Ti Alloys
}

\author{
S.E. Romankov, ${ }^{*}$ W. Sha, ${ }^{* *}$ S.D. Kaloshkin*** \\ * Institute of Physics \& Technology, 050032, Almaty32, Kazakhstan \\ ** Metals Research Group, School of Planning, Architecture and Civil Engineering, Queen's \\ University of Belfast, Belfast BT7 1NN, UK \\ *** Moscow State Institute of Steel and Alloys, Leninsky Prosp. 4, 119049, Moscow, Russia
}

$\mathrm{Ti}$ and its alloys have been applied to various industries. However, wearing behaviour and corrosion resistance need to be improved. Surface modification is one of the effective ways to improve these properties, and coatings based on titanium aluminides can be especially effective.

The Al film with thickness of about $6 \mu \mathrm{m}$ on the Ti-4Al-3Mo-1V substrate was formed by thermal deposition of $99.999 \% \mathrm{Al}$. By means of the mechanical alloying method, $\mathrm{Al}$ and $\mathrm{Al}+\mathrm{Ti}$ layers were deposited on the substrates. The samples and the powder along with the balls were placed into the mechano-reactor of vibration mill with frequency of $50 \mathrm{~Hz}$. During mechano-activation processing, the sample surface was impacted by a large number of flying balls along with particles of powder. The repeated ball collisions with the sample resulted in depositing a layer of powder on the surface. $\mathrm{Al}+\mathrm{Ti}$ overlayer was thicker than $\mathrm{Al}$ one. Ti addition promoted better deposition of powder on the surface.

During annealing of the samples, different aluminide phases were formed successively as the result of reactions between $\mathrm{Ti}$ and $\mathrm{Al}$. The temperature ranges of phase existence depended on the thickness of the initial layer. For thicker Al layer, a thicker overlayer was formed on the surface. Thicker overlayer required more time for its recrystallization and microstructural transformation.

In the process of heat treatment, the microstructural evolution of the overlayers depended on the thickness of the initial $\mathrm{Al}$ on the surface as well as the method of its deposition (Fig. 1). With Al layer, the sizes of micropits increased as annealing temperature rose, and after annealing at $1000^{\circ} \mathrm{C}$, a very fine hillock morphology was formed (Fig. 2a). With subsequent increasing temperature to $1100^{\circ} \mathrm{C}$, coalescence of the hillocks and leveling of structure happened (Fig. 2b). With Al+Ti layer, with increasing annealing temperature from $800^{\circ} \mathrm{C}$ to $900^{\circ} \mathrm{C}$, the microstructure on the sample became very inhomogeneous (Fig. 3). The overlayers produced by mechanical alloying method were more stable than the one produced by thermal deposition.

Mechanical attrition treatment and subsequent annealing could be used for fabrication of the overlayers with different phase compositions for the Ti-Al diffusion couples. Its advantages are:

- No special surface treatment requirement before deposition;

- Thick overlayer on the surface;

- Nanosized grain structure and a very good adherence;

- Cost.

Its disadvantages are:

- Rough and inhomogeneous structure;

- Strong distortion of samples. 

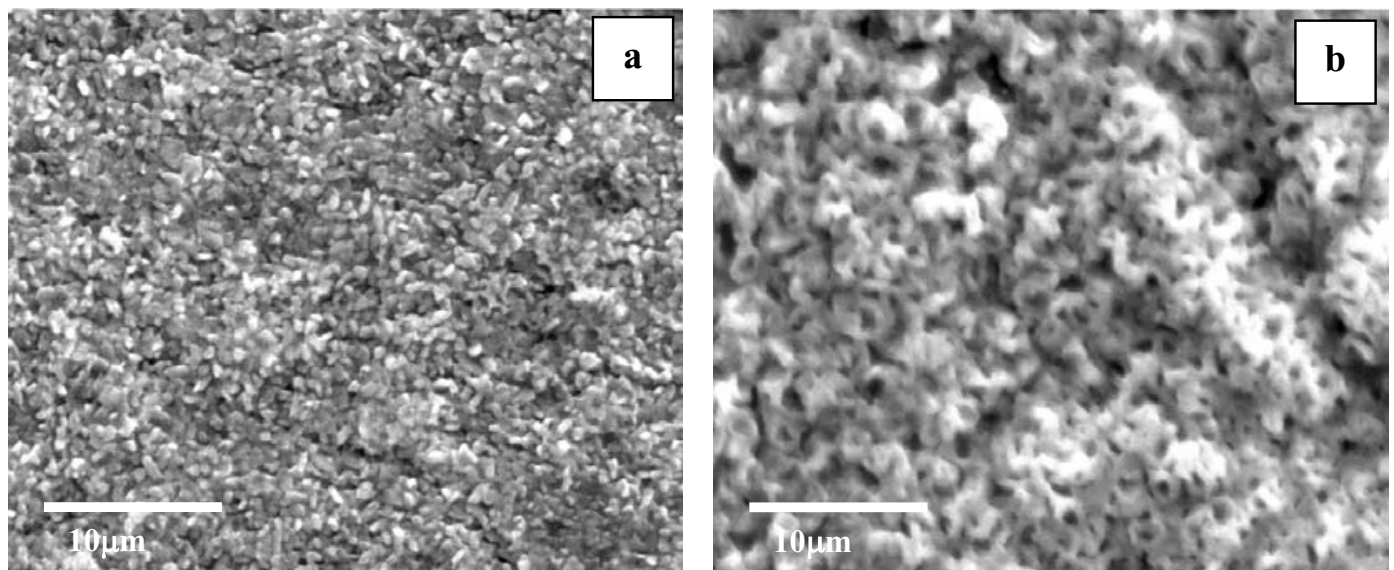

Fig. 1. Evolution of overlayer microstructure on the sample with Al. (a) Film produced by thermal deposition after annealing at $700^{\circ} \mathrm{C}$; (b) layer produced by MA method after annealing at $900^{\circ} \mathrm{C}$.
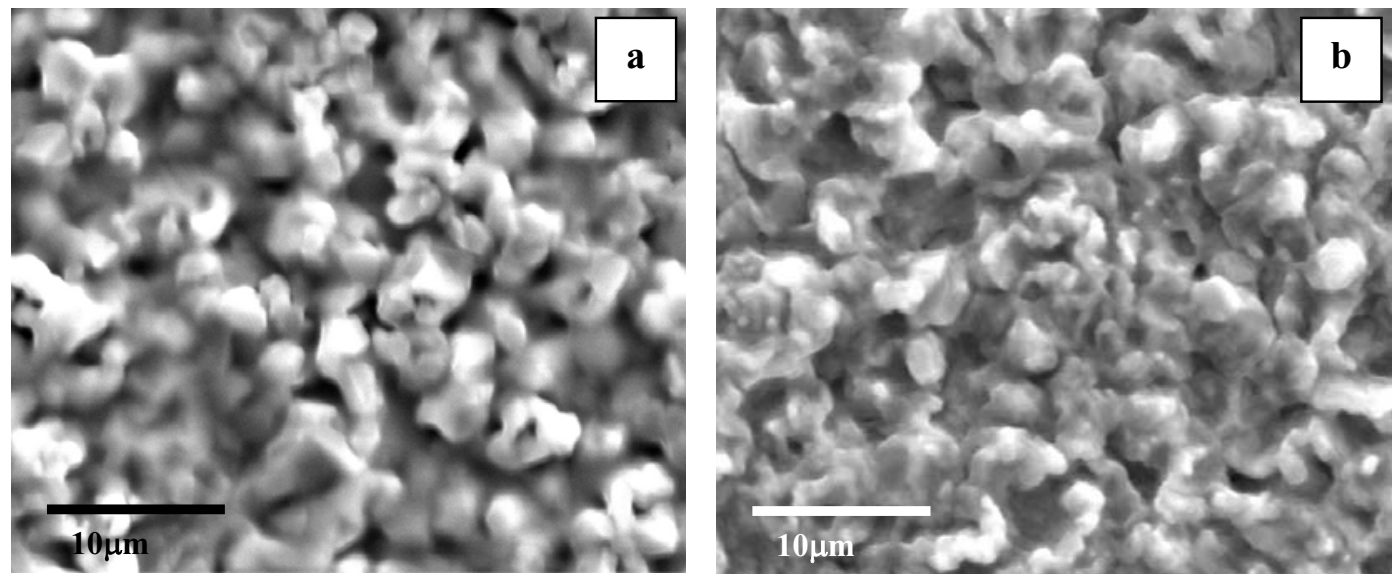

Fig. 2. Evolution of overlayer microstructure on the sample with Al layer produced by MA method after annealing at (a) $1000^{\circ} \mathrm{C}$ and (b) $1100^{\circ} \mathrm{C}$.
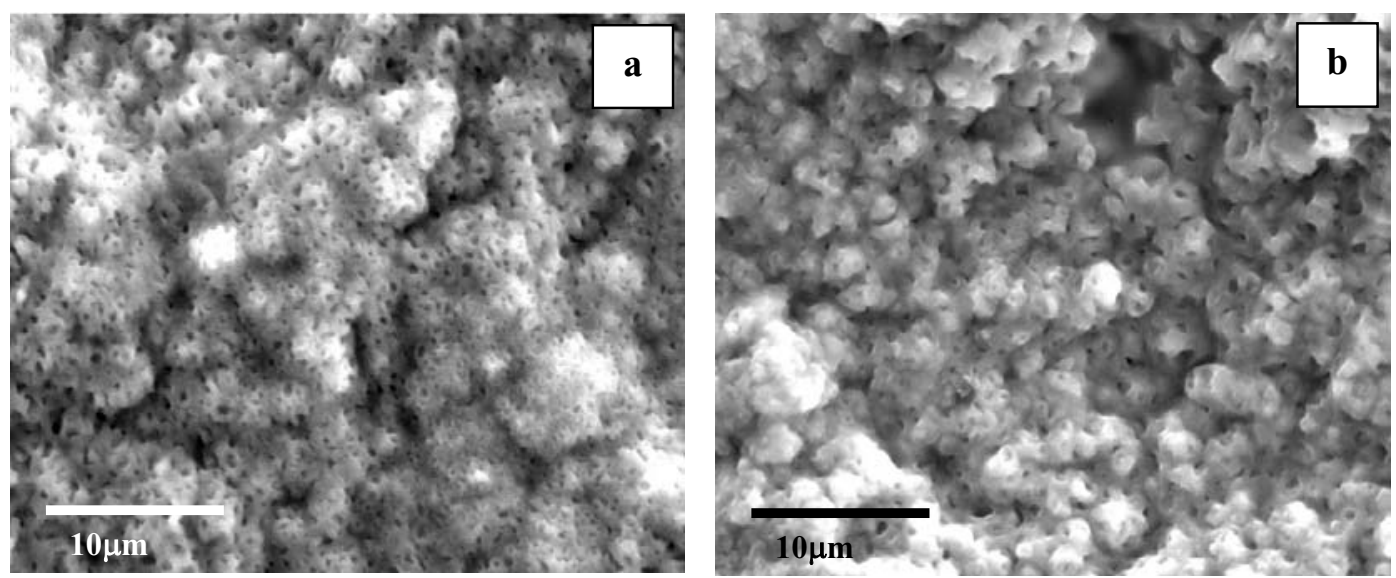

Fig. 3. Evolution of overlayer microstructure on the sample with $\mathrm{Al}+\mathrm{Ti}$ layer produced by MA method after annealing at (a) $900^{\circ} \mathrm{C}$ and (d) $1000^{\circ} \mathrm{C}$. 